\title{
Estimates of real economic activity in Switzerland, 1886-1930
}

\author{
Stefan Gerlach ${ }^{1}$, Petra Gerlach-Kristen ${ }^{2}$ \\ ${ }^{1}$ Bank for International Settlements, University of Basel and CEPR, Central bahnplatz 2, 4002 \\ Basel, Switzerland (e-mail: stefan.gerlach@bis.org) \\ ${ }^{2}$ Swiss National Bank and University of Basel, Börsenstr. 15, 8022 Zürich, Switzerland (e-mail: \\ petra.gerlach@snb.ch)
}

First version received: May 2002/Final version received: September 2004

\begin{abstract}
This paper uses annual data spanning 1870 to 1930 on a set of variables correlated with business conditions to construct an index of real economic activity in Switzerland. We extract an estimate of the common component of the data series using principal components analysis and the unobservable variables approach proposed by Stock and Watson (1989, 1991). The resulting index is similar to that constructed by Andrist et al. (2000) but displays more variation over time and is available for a longer time period. Moreover, it is less volatile and covers a longer time period in the 20th century than the estimate by Ritzmann-Blickenstorfer (1996).
\end{abstract}

Key words: Swiss economic history, principal components, coincident indicator

JEL Classification: E32, N13, N14

\section{Introduction}

The limited availability and poor quality of data is a major obstacle to empirical research on many episodes of historical interest. Although time series may be available on easily observed variables, such as consumer prices, exchange rates and interest rates, data on variables that need to be constructed are difficult to come by. In particular, it is frequently problematic to find measures of real economic activity, which plays a critical role in many macroeconomic events and analyses.

\footnotetext{
The views expressed in this paper are solely our own and are not necessarily shared by the institutions we are affiliated with. We thank the Editor and the anonymous referees for helpful comments (in particular for finding serious errors in the principal components analysis), and Jim Stock and Mark Watson for detailed explanations of their estimation strategy.
} 
This paper is concerned with the estimation of real economic activity in Switzerland before the start of the official national income data in 1929. Two earlier studies present such estimates. The first of these is Ritzmann-Blickenstorfer [9], RB below, which covers the years 1851 to 1913. This estimate is based on a number of data sources, ranging from employment to temperature, and its construction is described as at some points "adventurous" by the author (p. 521). This suggests that alternative estimates would be desirable.

The second study is by Andrist, Anderson and Williams [1], AAW in the following, which contains estimates of real output in Switzerland in the period 1914 to 1947 . The authors carefully consider possible indicators of real output and use qualitative judgement to construct an index of economic activity at an annual frequency. Between 1914 and 1922, the index is calculated as a three-year moving average of railway transportation data, between 1925 and 1929 as a moving average of industrial production, and for 1923 and 1924 as a combination of the two series. For the period 1930 to 1947, the authors use data on real national income.

While the AAW estimates appear plausible, they have two shortcomings. First, the authors do not use formal criteria to determine the choice of indicator time series, when to switch between them, and the degree to which they should be smoothed. Rather than letting the data decide what weight should be attached to the different time series, the authors do so on the basis of their views of the likely behaviour of economic activity in the period under consideration. Second, all estimates are inherently subject to uncertainty that ought to be characterised explicitly. The approach chosen by AAW does not allow for this. Overall, the authors' informal technique makes it difficult to judge the information content of the constructed output series, which suggests that additional estimates are of interest.

In this paper we rely on formal statistical techniques to construct two annual indices of real economic activity in Switzerland for the period 1886 to 1930. Our framework lets the data speak as to what information they contain about real output. Moreover, the statistical procedure allows us to compute confidence bands for real output growth for one of the indices. This indicates what we can, and can not, infer about cyclical fluctuations in the period studied.

The first measure is obtained by applying principal components (PC) analysis to a set of time series which are likely to co-vary with economic activity. While this is a simple way to assess output movements, it is not possible to derive confidence bands for this index. We therefore construct a second measure using the unobservable components (UC) approach proposed by Stock and Watson [10] and [11], SW in the following. This approach permits us to quantify the likely size of the estimation error, which is helpful for any subsequent econometric analysis of the data.

Before proceeding, we emphasise that, while econometric techniques can be helpful when conducting research on macroeconomic events in the distant past, they are at best a complement to, but no substitute for, careful historical analysis. Despite this, we hope that our estimates will prove useful to those interested in macroeconomic fluctuations in Switzerland before 1930.

The rest of the paper is organised as follows. In Sect. 2, we review a number of time series that are likely to contain information about real output in Switzerland, provide plots of the data and present unit root tests. In Sect. 3, we apply PC analysis to the time series and use the first component as a measure of economic activity. We find that the PC index computed on data 

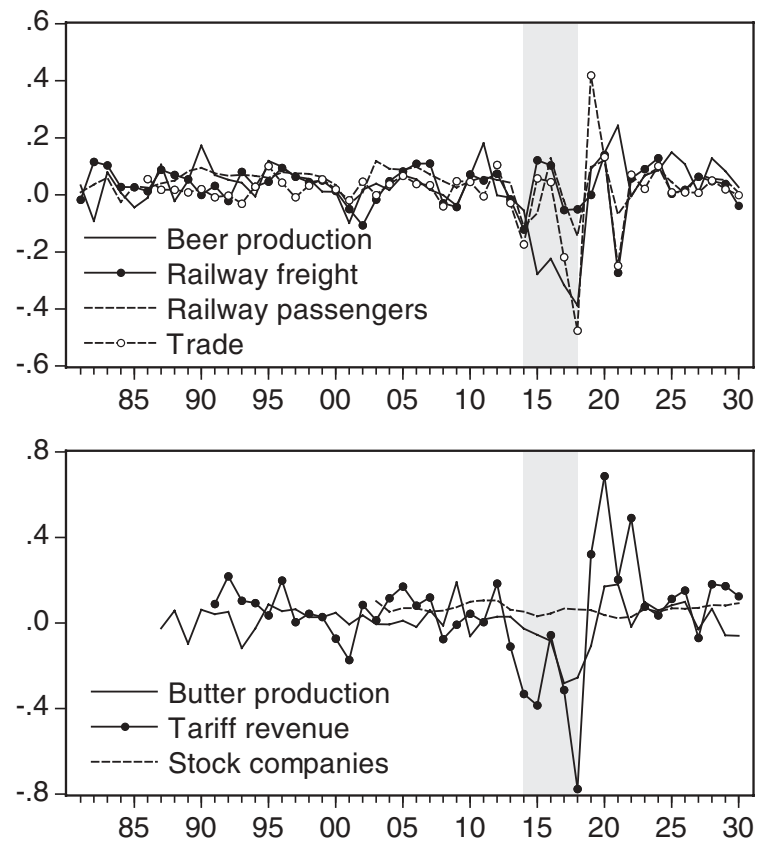

Fig. 1. Growth rates of indicator series

starting in 1886 seems to be a good measure of economic activity. In Sect. 4, we apply the UC approach suggested by SW to extract a measure of real output from the 1886 data set. In Sect. 5, we compare the UC estimate of real activity to alternative measures and argue that it seems to capture the business cycle well. Section 6 provides our conclusions. The Appendix presents details of the statistical methodology and the PC and UC estimates of the level of output for the years 1886 to 1930 .

\section{Data}

There is a limited number of time series available which can be used for the purpose at hand. We consider seven series which we group in five data sets depending on the length of the time span for which the data are available. The first set starts in 1880 and comprises the production of beer, railway freight and passenger numbers. ${ }^{1}$ To these variables, we by and by add time series with later starting dates to obtain other, increasingly larger, data sets. By considering also trade, for which data have been reported since 1885, we obtain the second data set. ${ }^{2}$ We deflate this series by the wholesale price index. The third group includes the production of butter and starts in 1886, while the fourth data set adds the tariff revenue on metal and machine imports

\footnotetext{
${ }^{1}$ Beer is available from 1870 onwards, as is a series on cheese production. We do not include the latter because it is highly correlated with butter production.

2 Trade is computed as the sum of imports and exports, which are highly correlated.
} 
Table 1. Unit root tests

\begin{tabular}{llc}
\hline \hline & Level & Change \\
\hline Beer production & -1.932 & $-3.908^{* *}$ \\
Railway freight & {$[-3.502]$} & {$[-3.504]$} \\
Railway passengers & -2.697 & $-7.245^{* * *}$ \\
& {$[-3.502]$} & {$[-3.504]$} \\
Trade & -1.093 & $-5.804^{* * *}$ \\
& {$[-3.502]$} & {$[-3.504]$} \\
Butter production & -2.527 & $-8.275^{* * *}$ \\
Tariff revenue & {$[-3.513]$} & {$[-3.515]$} \\
Number of stock companies & -2.098 & $-4.345^{* * *}$ \\
& {$[-3.515]$} & {$[-3.518]$} \\
& {$[-2.020$} & $-5.397^{* * *}$ \\
& {$[-3.527]$} & {$[-3.530]$} \\
\hline
\end{tabular}

Note: Trade and tariff revenue are deflated by the wholesale price index. We report the test statistics for Phillips-Perron tests including a trend, an intercept and a truncation lag of three over the available sample periods up to $1930 .{ }^{* * *}$ Indicates that the hypothesis of a unit root is rejected at the one percent level. Critical five percent values in brackets [ ].

(also deflated by the wholesale price index), which has been published since 1890. Finally, the fifth data set starts in 1902 and includes the number of stock companies. ${ }^{3}$ These data series reflect consumption, investment and trade, which together with government expenses form GDP. Since economy-wide fluctuations constitute business cycle swings, the common component of these series can be considered a measure of economic activity.

The series on stock companies stems from the Eidgenössisches Statistisches Amt [3], those on beer, butter, tariff revenue, nominal national income from 1938 onwards and the wholesale price index from RB [9], the railway and trade data from Mitchell [8], the nominal national income from 1929 to 1937 from the Swiss National Bank [12] and the consumer price index from Bordo and Jonung. ${ }^{4}$ Table 1 shows the test statistics of Phillips-Perron unit root tests. We perform this test since the data series grow over time and are likely to be non-stationary. We do not reject the hypothesis of a unit root in the logarithm of any of the indicator series, while the growth rates of all series except stock companies appear stationary. We therefore perform the econometric analysis on the once-differenced data. ${ }^{5}$

\section{Principal components analysis}

Figure 1 shows the growth rates of the indicator variables. The time series display close correlations and are most volatile around World War I (we

\footnotetext{
${ }^{3}$ The series number of stock companies is computed from the three time series "existing stock companies", "new stock companies" and "failed stock companies".

${ }^{4}$ The Bordo-Jonung data base is described in Bergman et al. [2].

5 We will omit "growth rate" for compactness whereever this is possible without causing confusion.
} 
Table 2. Fraction of variance explained by individual PCs

\begin{tabular}{|c|c|c|c|c|c|}
\hline & \multicolumn{5}{|c|}{ Data set starting in } \\
\hline & 1880 & 1885 & 1886 & 1890 & 1902 \\
\hline$\varphi_{1}$ & 0.659 & 0.613 & 0.572 & 0.732 & 0.743 \\
\hline$\varphi_{2}$ & 0.293 & 0.270 & 0.258 & 0.126 & 0.130 \\
\hline$\varphi_{3}$ & 0.048 & 0.090 & 0.076 & 0.066 & 0.058 \\
\hline$\varphi_{4}$ & & 0.027 & 0.073 & 0.035 & 0.033 \\
\hline$\varphi_{5}$ & & & 0.021 & 0.030 & 0.025 \\
\hline$\varphi_{6}$ & & & & 0.010 & 0.010 \\
\hline$\varphi_{7}$ & & & & & 0.002 \\
\hline
\end{tabular}

Note: $\varphi_{j}$ Denotes the fraction of the variance of the signal variables captured by the $j$ th PC.

mark war years in grey). The fact that the series move together suggests that they are all driven by the same underlying factor, which we may think of as aggregate economic activity. In this section, we apply PC analysis to extract this common component from the data.

Tables 2 and 3 show the results of the PC analysis of the data sets 1880, $1885,1886,1890$ and 1902. The procedure decomposes the $n$ time series of each set of indicator series into $n$ orthogonal factors, where the first of these, denoted as $y_{1}$, is that linear combination of the underlying indicator series which explains the largest fraction of their variances. ${ }^{6}$ This fraction of variances is given by

$$
\varphi_{1}=\frac{l_{1}}{\sum_{j=1}^{n} l_{j}},
$$

Table 3. Normalised factor loadings of the first PC

\begin{tabular}{llllll}
\hline \hline \multicolumn{7}{l}{ Data set starting in } & & \\
\cline { 2 - 5 } & 1880 & 1885 & 1886 & 1890 & 1902 \\
\hline Beer & $0.732^{* * *}$ & $0.343^{* * *}$ & $0.316^{* * *}$ & $0.188^{* * *}$ & $0.186^{* * *}$ \\
Freight & $(0.128)$ & $(0.066)$ & $(0.065)$ & $(0.020)$ & $(0.024)$ \\
& $0.060^{* * *}$ & $0.123^{* * *}$ & $0.080^{* * *}$ & $0.043^{* * *}$ & $0.041^{* * *}$ \\
Passengers & $(0.010)$ & $(0.024)$ & $(0.017)$ & $(0.005)$ & $(0.005)$ \\
Butter & $0.207^{* * *}$ & $0.159^{* * *}$ & $0.123^{* * *}$ & $0.073^{* * *}$ & $0.070^{* * *}$ \\
& $(0.036)$ & $(0.030)$ & $(0.025)$ & $(0.008)$ & $(0.009)$ \\
Trade & & $0.374^{* * *}$ & $0.193^{* * *}$ & $0.108^{* * *}$ & $0.110^{* * *}$ \\
Tariff & $(0.072)$ & $(0.040)$ & $(0.012)$ & $(0.014)$ \\
& & & $0.288^{* * *}$ & $0.169^{* * *}$ & $0.175^{* * *}$ \\
Companies & & $(0.059)$ & $(0.018)$ & $(0.022)$ \\
& & & $0.418^{* * *}$ & $0.418^{* * *}$ \\
& & & $(0.045)$ & $(0.053)$ \\
\hline
\end{tabular}

Note: Standard errors in parentheses ()$.^{* * *}$ Denotes significance at the one percent level. The factor loadings are obtained from the normalised first eigenvector.

\footnotetext{
${ }^{6}$ For a discussion of the PC analysis, see e.g., Johnston [6] and Mardia et al. [7].
} 
where $l_{j}$ denotes the $j$ th eigenvalue of the covariance matrix $S$ of the indicator series. Table 2 shows $\varphi_{1}$ to $\varphi_{n}$ for the five data sets, while Table 3 reports the factor loadings of the first PC. These loadings correspond to the elements of the first eigenvector $b_{1}$ of $S$ and have been normalised such that they sum to unity. We also report their (normalised) standard errors, which are computed as

$$
s\left(b_{k 1}\right)=\sqrt{\frac{l_{1}}{T} \sum_{j=2}^{n} \frac{l_{j}}{\left(l_{1}-l_{j}\right)^{2}} b_{k 1}^{2}} \text { for } k=1, \ldots, n,
$$

where $b_{k 1}$ is the $k$ th element of $b_{1}$ and $T$ the sample length (see Mardia et al. [7], p. 230).

To understand the PC analysis, consider the first column of results in Table 2, which reports the $\varphi$ s for the 1880 data set, which consists of beer, freight and passengers. The first line indicates that $y_{1,1880}$ explains $65.9 \%$ of the variance of the three series (implying that $y_{2,1880}$ and $y_{3,1880}$ together explain the remaining $34.1 \%$ ). The factor loadings in the first column of Table 3 suggest that we attach the largest weight in the construction of $y_{1,1880}$ to beer, the most volatile of the indicator variables, and less weight to freight and passengers. ${ }^{7}$ The second column in Table 2 presents the PC analysis for the 1885 set. We find that $\varphi_{1,1885}=61.3 \%$, so that the second to fourth PCs account for the remaining $38.7 \%$.

Which data set should we use to construct our PC index of economic activity? To shed light on this question, we perform sphericity tests on the $n$ eigenvalues of each data set. These tests allow us to judge the relative importance of the $n$ PCs within one data set. The test statistic is given by

$$
T(n-k) \log \frac{\frac{1}{n-k} \sum_{j=k+1}^{n} l_{j}}{\left(\prod_{j=k+1}^{n} l_{j}\right)^{1 /(n-k)}} \sim \chi_{0.5(n-k+2)(n-k-1)}^{2} \text { for } k=0, \ldots, n-1
$$

Table 4. Sphericity tests (p-values)

\begin{tabular}{lllllll}
\hline \hline \multicolumn{7}{c}{ Data set starting in } \\
\cline { 3 - 6 }$k=$ Null hypothesis & 1880 & 1885 & 1886 & 1890 & 1902 \\
\hline 0 & All $l$ equally important & 0.000 & 0.000 & 0.000 & 0.000 & 0.000 \\
1 & All but $l_{1}$ equally important & 0.000 & 0.000 & 0.000 & 0.000 & 0.000 \\
2 & All but $l_{1}$ and $l_{2}$ equally important & & 0.000 & 0.371 & 0.000 & 0.000 \\
3 & All but $l_{1}$ to $l_{3}$ equally important & & & 0.199 & 0.006 & 0.286 \\
4 & All but $l_{1}$ to $l_{4}$ equally important & & & & 0.002 & 0.590 \\
5 & All but $l_{1}$ to $l_{5}$ equally important & & & & & 0.343 \\
\hline
\end{tabular}

\footnotetext{
${ }^{7}$ An earlier version of the paper (Gerlach and Gerlach-Kristen [4]) performs the PC analysis on the correlation, rather than the covariance, matrix of the indicator variables. This approach yields roughly equal weights on beer, freight and passengers and a smoother PC index.
} 
(see Mardia et al. [7], p. 235). Setting $k=0$ gives a test of the hypothesis that all eigenvalues are equal, i.e., that all $\varphi$ s account for an equal fraction of the variance of the underlying time series. If this test rejects, it follows that at least one PC is more informative than the others in the sense that it accounts for a larger fraction of the variance of the underlying series than the other components. Next, we set $k=1$, thereby dropping $l_{1}$ from the analysis, and redo the test. Since we start by excluding the most informative PC, the acceptance of the null hypothesis suggests that the remaining PCs are equally important. To see how we can make use of this information in practice, consider Table 4, which shows that in the 1880 data set, we reject for $k=0$ and 1. Thus, the three PCs seem to differ in importance, which is not surprising given that $\varphi_{1}=0.66, \varphi_{2}=0.29$ and $\varphi_{3}=0.05$ in Table 2 . We also find differences in importance for all $n$ eigenvalues of the 1885 and the 1890 set. By contrast, we do not reject that $l_{3}$ to $l_{5}$ are of equal importance for the $1886 \mathrm{set}$, and for the 1902 set $l_{4}$ to $l_{7}$ appear equally important. This seems due to the fact that $\varphi_{2,1886}$ and $\varphi_{3,1902}$ are considerably larger than $\varphi_{3,1886}$ and $\varphi_{4,1902}$, respectively. One interpretation of this finding is that most of the variance of the signal series in these data sets is explained by "few" PCs, suggesting that the first of these is a natural measure of the business cycle component.

Since our goal is to construct an index of economic activity which reaches as far back in time as possible, $y_{1,1886}$ seems suitable. To assess whether it contains largely the same information as $y_{1,1902}$, consider the correlations of the different $y_{1} \mathrm{~s}$ in Table 5. All correlations are larger than 0.84 , and for the 1886 data set, the correlation with $y_{1,1890}$ and $y_{1,1902}$ is above 0.91 . In particular, $y_{1,1886}$ is strongly correlated with $y_{1,1902}$, which uses the largest number of indicator variables and therefore the largest information set. By contrast, the correlations of $y_{1,1880}$ and $y_{1,1885}$ with $y_{1,1902}$ are lower.

Overall, we interpret these findings as suggesting that $y_{1,1886}$ contains much the same information as $y_{1,1890}$ and $y_{1,1902}$, and we therefore use it as our PC index. The index is constructed as a weighted average of the growth rates of beer, freight, passengers, butter and trade. The respective weights in the construction of the index are given in the third column in Table 3 as 0.32 , $0.08,0.12,0.19$ and 0.29 , so that the signal series appear roughly equally important. 8

To further explore the characteristics of the PC index, we calculate the cross-correlation between the underlying signal series at time $t$ and the PC index at time $t+1$. We find no clearly significant cross-correlations, which suggests that none of the underlying variables is a leading indicator of the business cycle. ${ }^{9}$ The PC index itself, however, displays signs of first-order autocorrelation. ${ }^{10}$

\footnotetext{
${ }^{8}$ However, a formal test for equal loadings in the eigenvector, the statistics for which is given by $(T-1)\left(l_{1} r^{\prime} S^{-1} r+l_{1}^{-1} r^{\prime} S r-2\right) \sim \chi_{n-1}^{2}$, where the vector $r$ obeys $r^{\prime} r=1$ (see Mardia et al. [7], p. 233 ), rejects this hypothesis (p-value of 0.00 ). The hypothesis that one factor loading equals zero while the others are identical is rejected for all cases (p-value for each test is 0.00 ).

${ }^{9}$ In the case of beer, we reject the hypothesis of no significant cross-correlation at the one, but not the five, percent level.

${ }^{10}$ A Q-test rejects the hypothesis of no first-order serial correlation at the five percent level.
} 
Table 5. Correlations of first PCs

\begin{tabular}{lllll}
\hline \hline & $y_{1}, 1880$ & $y_{1}, 1885$ & $y_{1}, 1886$ & $y_{1}, 1890$ \\
\hline$y_{1}, 1885$ & 0.848 & & & \\
$y_{1}, 1886$ & 0.901 & 0.975 & & \\
$y_{1}, 1890$ & 0.853 & 0.901 & 0.918 & \\
$y_{1}, 1902$ & 0.855 & 0.908 & 0.929 & 1.000 \\
\hline
\end{tabular}

Note: Correlations computed using pair-wise samples.

\section{Unobserved components analysis}

The PC index has the shortcoming that we cannot assess the precision with which we have estimated the common component. We therefore turn to the UC model, proposed by SW, which allows us to do so.

We assume that the researcher observes a vector $Z_{t}$ that contains variables correlated with the level of economic activity. In our case, $Z_{t}$ is a $5 \times 1$ vector holding the level series of beer, butter, freight, passengers and trade. These series are assumed to be linearly related to the unobserved current and, possibly, lagged level of real output, $C_{t}$, which is a scalar. Thus,

$$
Z_{t}=\mu t+b_{1} C_{t}+b_{2} C_{t-1}+e_{t},
$$

where $\mu$ is a $5 \times 1$ vector, $t$ is a time trend, $e_{t}$ a $5 \times 1$ vector containing unobserved disturbances, and where the $5 \times 1$ vectors $b_{1}$ and $b_{2}$ reflect the impact of current and lagged economic activity on the indicator series. We assume that the covariance matrix of $e_{t}$ is diagonal. Note that the $e_{t}$ vector can be interpreted as allowing for (potentially non-stationary) measurement errors. Moreover, since the elements of $\mu$ may differ, the indicator series can have different average growth rates. Defining $X_{t} \equiv \Delta Z_{t}$, we difference Eq (1) to yield

$$
X_{t}=\mu+b_{1} \Delta C_{t}+b_{2} \Delta C_{t-1}+\Delta e_{t},
$$

where we assume that the elements of $\Delta e_{t}$ are normally distributed and serially uncorrelated. Equation (2) thus states that the growth rate of each indicator series is given by a constant, the current and lagged growth rate of economic activity and a shock.

SW suggest estimating Eq. (2) using the normalised $X_{t}$ series. We define $Y_{i, t} \equiv\left(X_{i, t}-\mu_{i}\right) / \sigma_{i}, \beta_{i} \equiv b_{i} / \sigma_{i}$ and $\varepsilon_{i, t} \equiv \Delta e_{i, t} / \sigma_{i}$, where $\mu_{i}$ and $\sigma_{i}$ denote the mean and standard error of indicator series $i$, respectively, and obtain

$$
Y_{t}=\beta_{1} \Delta C_{t}+\beta_{2} \Delta C_{t-1}+\varepsilon_{t} .
$$

Since only beer and butter display signs of first-order autocorrelation, we set the third to fifth element of $\beta_{2}$ equal to zero.

We assume that $\Delta C_{t}$ obeys an $\mathrm{AR}(1)$ process since the PC index of economic activity displays first-order serial correlation, so that

$$
\Delta C_{t}=\delta+\alpha \Delta C_{t-1}+u_{t},
$$

where $\delta$ is the mean growth rate of real output and $u_{t}$ a white noise disturbance. Equations (3) and (4) constitute a state-space system in which the indicator series take the role of signals, while economic activity is the state variable. Hamilton [5] shows that if the disturbances in such a system are 
Table 6. State space estimates

\begin{tabular}{|c|c|c|c|c|c|c|}
\hline Sample & $\begin{array}{l}\text { Model 1 } \\
1886-1930\end{array}$ & & $\begin{array}{l}\text { Model } 2 \\
1886-1930 \\
\text { (disregarding } \\
\text { WWI) }\end{array}$ & & $\begin{array}{l}\text { Model } 3 \\
1886-1950\end{array}$ & \\
\hline \multirow[t]{2}{*}{$\alpha$} & 0.157 & & 0.242 & & -0.035 & \\
\hline & $(0.188)$ & - & $(0.186)$ & - & $(0.371)$ & - \\
\hline \multirow[t]{2}{*}{$\beta_{1, b e}$} & $0.576^{* * *}$ & $0.569^{* * *}$ & 0.094 & & $0.396^{* *}$ & $0.372^{* * *}$ \\
\hline & $(0.100)$ & $(0.082)$ & $(0.198)$ & & $(0.199)$ & $(0.065)$ \\
\hline \multirow{2}{*}{$\beta_{2, b e}$} & $0.476^{* * *}$ & $0.473^{* * *}$ & & & $0.411^{* *}$ & $0.401^{* * *}$ \\
\hline & $(0.165)$ & $(0.117)$ & - & - & $(0.199)$ & $(0.138)$ \\
\hline \multirow[t]{2}{*}{$\beta_{1, b u}$} & 0.365 & $0.372^{* *}$ & -0.194 & $-0.269^{* *}$ & 0.202 & \\
\hline & $(0.346)$ & $(0.181)$ & $(0.178)$ & $(0.113)$ & $(0.420)$ & - \\
\hline \multirow[t]{2}{*}{$\beta_{2, b u}$} & $0.552^{* * *}$ & $0.548^{* * *}$ & & & & \\
\hline & $(0.199)$ & $(0.125)$ & - & - & - & - \\
\hline \multirow[t]{2}{*}{$\beta_{1, f}$} & $0.514^{* * *}$ & $0.528^{* * *}$ & $0.660^{* * *}$ & $0.804^{* * *}$ & $0.637^{* * *}$ & $0.637^{* * *}$ \\
\hline & $(0.139)$ & $(0.128)$ & $(0.235)$ & $(0.157)$ & $(0.090)$ & $(0.090)$ \\
\hline \multirow[t]{2}{*}{$\beta_{1, p}$} & $0.761^{* * *}$ & $0.769^{* * *}$ & $0.970^{* * *}$ & $0.841^{* * *}$ & $0.846^{* * *}$ & $0.860^{* * *}$ \\
\hline & $(0.157)$ & $(0.106)$ & $(0.217)$ & $(0.102)$ & $(0.082)$ & $(0.065)$ \\
\hline \multirow[t]{2}{*}{$\beta_{2, p}$} & - & - & - & - & $0.430^{* * *}$ & $0.450^{* * *}$ \\
\hline & & & & & $(0.092)$ & $(0.067)$ \\
\hline \multirow[t]{2}{*}{$\beta_{1, t}$} & $0.834^{* * *}$ & $0.866^{* * *}$ & $0.481^{* *}$ & $0.583^{* * *}$ & $0.840^{* * *}$ & $0.815^{* * *}$ \\
\hline & $(0.111)$ & $(0.106)$ & $(0.206)$ & $(0.191)$ & $(0.106)$ & $(0.111)$ \\
\hline Log likelihood & -266.841 & -267.174 & -288.046 & -226.460 & -267.480 & -206.281 \\
\hline
\end{tabular}

Note: Maximum likelihood estimates of Eqs. (3) and (4). ${ }^{* *},{ }^{* *}$ Denotes significance at the $5 / 1 \%$ level. Standard errors in parentheses.

normally distributed, which we assume, it can be estimated using Kalman filtering. SW demonstrate how to extract an estimate of $\Delta C_{t}$, and we apply a two-sided smoother to do so. ${ }^{11}$

SW make the identifying assumption that $\sigma_{u}^{2}$ equals unity. The first column in Table 6 presents the estimates of $\alpha, \beta_{1}$ and $\beta_{2}$ using the five signal series of the 1886 to 1930 set (we refer to this as Model 1 and discuss Models 2 and 3, which assume different sample periods, in Sect. 4). Since we do not reject the hypothesis that $\alpha$ equals zero, we present in the second column the estimates of the restricted system. ${ }^{12}$ It thus appears that $C_{t}$ follows a random walk with drift. For reference below, we also report estimations using a data set which disregards the war years and an alternative set with data up to 1950, which we discuss in Sect. $4 .^{13}$

Appendix A shows how the SW methodology allows us to calculate economic growth as a weighted average of the current and once-lagged signal

\footnotetext{
${ }^{11}$ A two-sided smoother makes use of the information available over the entire sample period, while a one-sided smoother constructs an estimate of the unobserved variable at time $t$ using information only up to $t$. SW use a one-sided smoother since they estimate current economic activity. We apply a two-sided smoother since we are interested in historical estimates of real activity.

${ }^{12}$ A $\log$ likelihood test does not reject the hypothesis that $\alpha=0$ (p-value $=0.41$ ).

${ }^{13}$ We include $\Delta C_{t-1}$ only for those time series which display first-order autocorrelation in the sample period studied.
} 
Table 7. Weighting vector for signal series and average growth rate of economic activity

\begin{tabular}{llll}
\hline \hline Sample & $\begin{array}{l}\text { Model 1 } \\
1886-1930\end{array}$ & $\begin{array}{l}\text { Model 2 } \\
1886-1930 \\
\text { (disregarding WWI) }\end{array}$ & $\begin{array}{l}\text { Model 3 } \\
1886-1930\end{array}$ \\
\hline$\gamma_{b e}^{(1)}$ & 12.21 & - & 4.53 \\
$\gamma_{b u}^{(1)}$ & 5.11 & -3.99 & - \\
$\gamma_{f r}^{(1)}$ & 9.02 & 31.34 & 5.18 \\
$\gamma_{p}^{(1)}$ & 23.11 & 39.63 & 78.76 \\
$\gamma_{t}^{(1)}$ & 42.56 & 12.15 & 14.87 \\
$\delta$ & 2.44 & 2.14 & 3.37 \\
\hline
\end{tabular}

Note: Values in percent.

series. The weights for the current growth rates of beer, butter, freight, passengers and trade are given by a $5 \times 1$ vector $\gamma^{(1)}$, which is provided in the column for Model 1 in Table 7. We also present $\delta$, the estimate of the average growth rate of the UC index over the period 1886 to 1930 , which equals 2.4 percent and thus is larger than the average growth rate of the PC index. Compared to our first measure of real economic activity, we furthermore attribute less weight to the data on beer, butter and freight and more weight to the passengers and trade series.

\section{Alternative estimates}

In this section we compare the UC index with alternative estimates and actual real national income data. First, we contrast it with the PC index and find that they evolve in similar ways over time. Second, we consider other estimates from the literature and argue that the UC index seems more realistic. Third, we compare the static forecasts of our UC index for the 1930s and 40s with actual national income data and find a close fit. Fourth, we consider estimates of the UC index using different sample periods.

To judge the differences of the alternative estimates, we include the confidence band for the UC index. ${ }^{14}$ While this band is rather broad, which suggests that the UC index only provides us with a rough estimate of real activity, there is no reason to believe that the other measures, which do not allow the calculation of a standard error, yield more reliable estimates of the business cycle.

\subsection{Comparison with PC Index}

Figure 2 plots the PC and the UC index. In comparing these two series, it has to be noted that the PC index is based on the "raw" data, while the UC index

\footnotetext{
${ }^{14}$ The confidence band does not incorporate parameter uncertainty. Hamilton [5] discusses how it can be taken into account.
} 


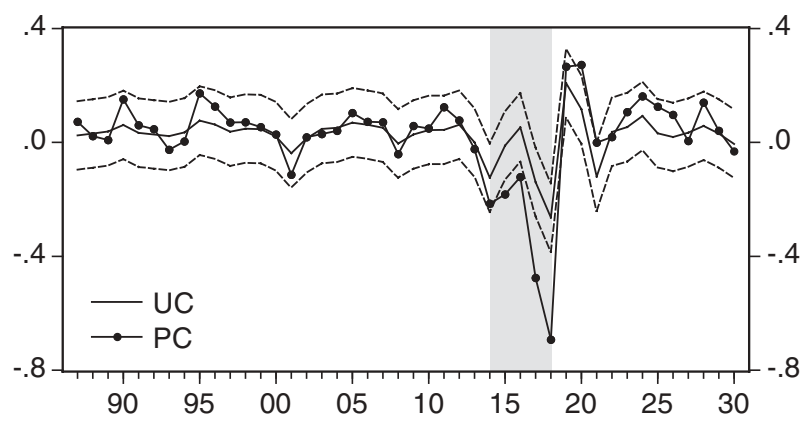

Fig. 2. The UC and PC indices

is constructed using the normalised series. ${ }^{15}$ As a consequence, the PC analysis attaches greater weight to more volatile series than the UC approach and therefore is more volatile. In particular, the PC index suggests a significantly sharper contraction of economic activity during World War I than the UC index. Nevertheless, Table 8 reports that the two series have a correlation of 0.89 .

Do our PC and UC indices match the historical evidence? ${ }^{16}$ Our estimates suggest that growth was mostly positive and quite smooth in the first years of the sample, but that there was a small reduction in the expansion rate at the beginning of the 1890 s, which might be due to falling exports. The slump in activity in 1901 is most likely due to a collapse in primary goods prices and the consequent investment crisis, while the decline in growth in 1908 could

Table 8. Correlations of the estimates of real economic activity

Correlation with UC

(Model 1 in Tables 6 and 7)

\begin{tabular}{ll}
\hline UC (Model 1 in Tables 6 and 7) & 1 \\
PC & 0.889 \\
RB & 0.459 \\
AAW & 0.754 \\
Real national income & 0.594 \\
UC (Model 2 in Tables 6 and 7) & 0.867 \\
UC (Model 3 in Tables 6 and 7) & 0.712 \\
\hline
\end{tabular}

Note: UC denotes the unobserved components, $\mathrm{PC}$ the principal components index, RB the index by Ritzmann-Blickenstorfer [9] and AAW that by Andrist, Anderson and Williams [1].

\footnotetext{
${ }^{15}$ Gerlach and Gerlach-Kristen [4] perform the PC analysis on the correlation, rather than the covariance, matrix of the original data. By effectively normalising the indicator series, they obtain a PC index that tracks the UC index even more closely than the one presented here.

${ }^{16}$ For a more detailed discussion of economic events in Switzerland between 1870 and 1930, the interested reader is referred to the working paper version of this article (Gerlach and GerlachKristen [4]) and the references therein.
} 

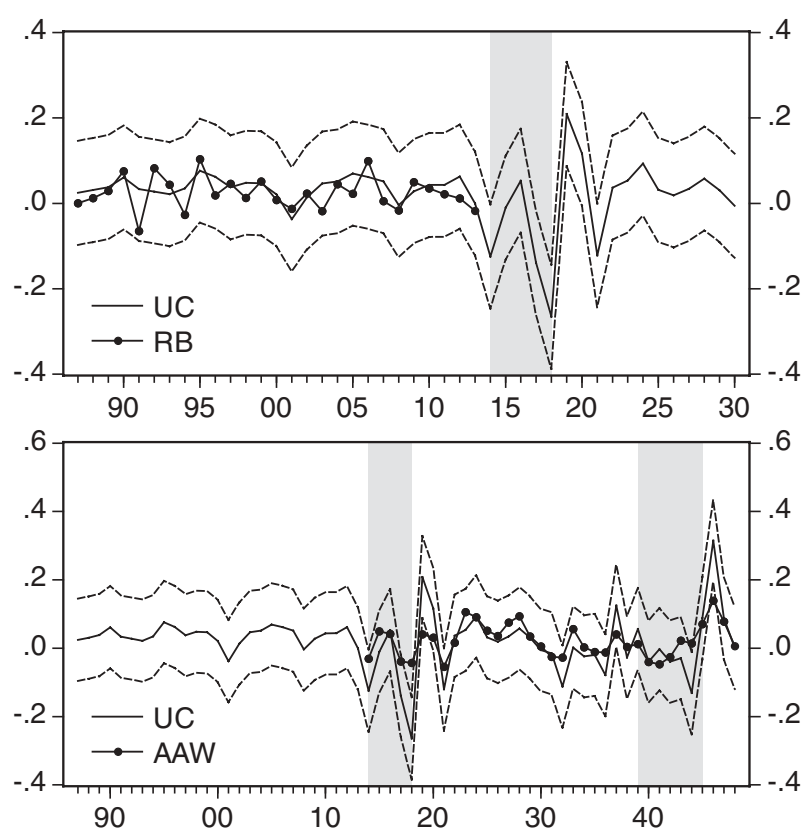

Fig. 3. UC index and alternative estimates from the literature

reflect that year's financial crisis, which affected asset markets worldwide. In 1914 Swiss economic activity contracted sharply, which can be attributed to the onset of World War I. In the following two years, growth in neutral Switzerland recovered somewhat, which may have been related to the increased import demand of the parties at war. The PC and UC indices show furthermore that the last two years of the war brought a collapse in growth, which most likely resulted from decreased external demand. In 1919 output rebounded due to an expansion of trade associated with the end of hostilities. The estimates suggest that the Swiss economy experienced a recession in 1921, which coincided with a weakness of global economic conditions, the depreciation of the currencies of Switzerland's neighbours and the resulting loss of competitiveness. Following the stabilisation of the mark at the end of 1923, economic activity in Switzerland expanded for a number of years, but output growth declined to zero in 1930, the year that for Switzerland marked the onset of the Depression. In sum, the activity indices resulting from the PC and UC analysis appear to reflect the historical evidence on business fluctuations quite well.

\subsection{Comparison with estimates from the literature}

Next, we compare the UC index to estimates of real economic activity which have been proposed in the literature. The upper panel in Fig. 3 shows the path 


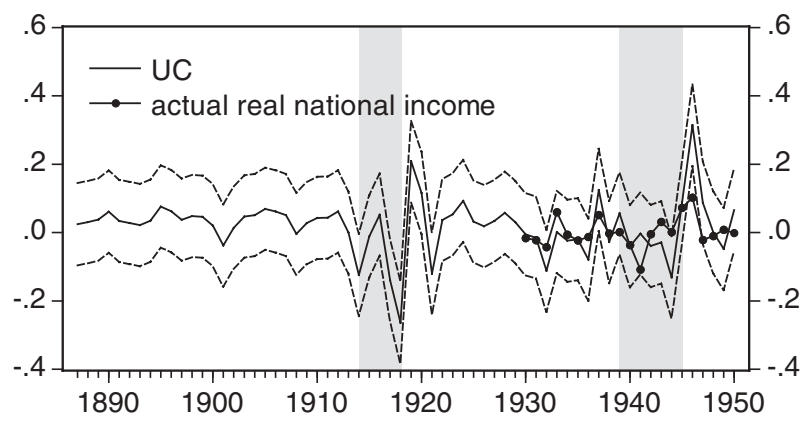

Fig. 4. UC index and actual real national income

of the real GDP constructed by RB. ${ }^{17}$ While the RB estimates lie within the confidence band of our UC index, they display more variability. Table 8 reports a correlation coefficient of 0.46 .

The lower panel in Fig. 3 depicts the AAW estimate of the business cycle. Since this data series ends in 1948, we extend the UC index. To do so, we apply the weights estimated for the signal series over the period 1886 to 1930 to the observations from 1931 to 1950 (World War II also is marked in grey). Table 8 indicates that this extended UC series and the AAW measure have a correlation coefficient of 0.75 . As is visible in the lower plot, the AAW estimate lies within the UC confidence interval after 1919. During World War I, however, the AAW series displays considerably less volatility than our estimate of economic activity. In fact, the fluctuations of the AAW index during that war are about as large as in the following decades. Since World War I is likely to have caused considerable economic dislocation, the UC index, which is more volatile during than after the war, seems the preferable measure.

\subsection{Comparison with real national income}

Figure 4 compares the UC index with actual real national income data, the growth rate of which is available from 1930 onwards. ${ }^{18}$ The two series appear closely related, which is confirmed in Table 8 by a correlation coefficient of 0.59 . Notably, the correlation over the $1930 \mathrm{~s}$ is higher $(0.72)$ than in the following decade. It could be argued that the poorer fit of our measure of real activity in the 1940s might be due to changes in the structure of the economy associated with the shift to a war-time economy.

In sum, Figs. 2 to 4 suggest that our estimate of real economic activity captures the actual business cycle in Switzerland quite well.

\footnotetext{
${ }^{17}$ We use the measure of real economic activity which has been deflated with the GDP deflator (RB, p. 866).

${ }^{18}$ We deflate nominal national income data using the consumer price index.
} 


\subsection{Alternative sample periods}

Since economic conditions in Europe in the first half of the twentieth century were turbulent, it might be suspected that the path of the UC index is sensitive to the exact data sample chosen. We consider two alternative specifications and compare them with the original Model 1. Model 2 "dummies out" the years of World War I in the estimation of $\gamma$ by setting the 1914 to 1918 values of the signal series equal to their means. Model 3 extends the sample period on which the weights are estimated to 1950 .

The estimation output in Tables 6 and 7 indicates that the weights attached to the individual signal series differ somewhat between the alternative sample specifications. However, the estimated paths of the UC index in Fig. 5 are similar, as is evidenced by their high correlations reported in Table 8 ( 0.87 for Models 1 and 2, 0.71 for Models 1 and 3). As with the actual national income data, we find that the fit between Model 1 and Model 3 deteriorates in the 1940s. ${ }^{19}$ This again suggests a shift in the structure of the economy during the Second World War. Overall, the alternative specifications of the UC index indicate that our estimate of real economic activity is robust to changes in the data sample.
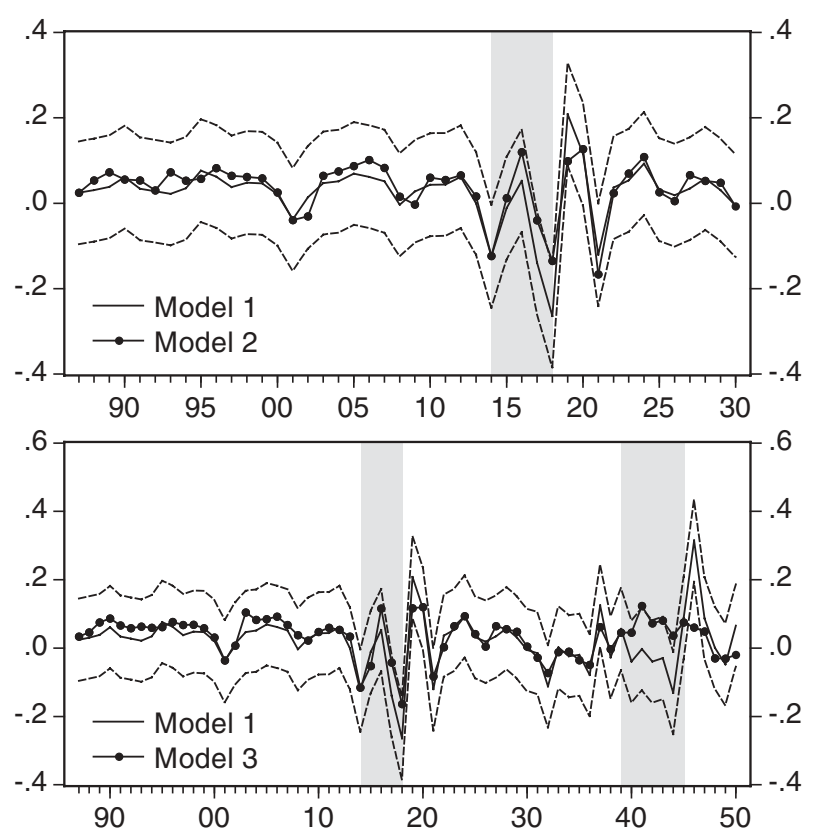

Fig. 5. Comparison of alternative UC specifications

\footnotetext{
${ }^{19}$ The correlation between the two indices for the sample period 1886 to 1940 is 0.89 .
} 


\section{Conclusions}

In this paper we use principal and unobserved components methods to assess real economic activity in Switzerland between 1886 to 1930. The two methods yield similar growth estimates which can be linked to the beginning of the official data series on economic activity. Moreover, our PC and UC indices, which let the data speak as to what weights to attach to the underlying signal series, are roughly in line with existing estimates that have relied on informal methods. We find, however, evidence of more volatility during, and less after, World War I than the study of Andrist, Anderson and Williams, which reports no unusual fluctuations for the war years, and argue that our estimates therefore appear more realistic.

One interesting finding of practical econometric interest is that the PC index is similar to the UC index. In general, the latter method is better able to capture dynamics in the underlying factors. However, in this specific case there appears to be little time series structure to the common factor, so that the principal components index therefore performs quite well. It would be interesting to see whether the two methods would give similar estimates also for other time periods. We end by reiterating that any careful analysis of economic activity in Switzerland in the period studied here should rely on better historical judgement than we can offer. Despite this, we hope that the analysis presented in this paper will spark more research in this interesting area.

\section{Appendix A: Derivation of the UC index}

Rewrite Eq. (3) as

$$
\left[\begin{array}{c}
\Delta C_{t} \\
\Delta C_{t-1} \\
C_{t-1}
\end{array}\right]=\left[\begin{array}{l}
\delta \\
0 \\
0
\end{array}\right]+\left[\begin{array}{lll}
\alpha & 0 & 0 \\
1 & 0 & 0 \\
1 & 0 & 1
\end{array}\right]\left[\begin{array}{c}
\Delta C_{t-1} \\
\Delta C_{t-2} \\
C_{t-2}
\end{array}\right]+\left[\begin{array}{c}
u_{t} \\
0 \\
0
\end{array}\right],
$$

where we define for reference below

$$
A \equiv\left[\begin{array}{ccc}
\alpha & 0 & 0 \\
1 & 0 & 0 \\
1 & 0 & 1
\end{array}\right] .
$$

Assume for compactness the case of $n=2$ signal variables. The Kalman filter then fits the observation equation

$$
\left[\begin{array}{l}
Y_{1, t} \\
Y_{2, t}
\end{array}\right]=\left[\begin{array}{lll}
\beta_{11} & \beta_{12} & 0 \\
\beta_{21} & \beta_{22} & 0
\end{array}\right]\left[\begin{array}{c}
\Delta C_{t} \\
\Delta C_{t-1} \\
C_{t-1}
\end{array}\right]+\left[\begin{array}{l}
\varepsilon_{1, t} \\
\varepsilon_{2, t}
\end{array}\right],
$$

where we define

$$
B \equiv\left[\begin{array}{lll}
\beta_{11} & \beta_{12} & 0 \\
\beta_{21} & \beta_{22} & 0
\end{array}\right]
$$

and 


$$
E \equiv\left[\begin{array}{cc}
\sigma_{\varepsilon 1}^{2} & 0 \\
0 & \sigma_{\varepsilon 2}^{2}
\end{array}\right]
$$

We denote the $3 \times 3$ covariance of the forecast error as $P$ and let $I_{k}$ stand for a $k \times k$ identity matrix. SW then show that $\Delta C_{t}$ can be estimated as

$$
\Delta C_{t}=\delta+\left[\begin{array}{ll}
\gamma_{1}^{(1)} & \gamma_{2}^{(1)}
\end{array}\right]\left[\begin{array}{l}
Y_{1, t} \\
Y_{2, t}
\end{array}\right]+\left[\begin{array}{ll}
\gamma_{1}^{(2)} & \gamma_{2}^{(2)}
\end{array}\right]\left[\begin{array}{c}
Y_{1, t-1} \\
Y_{2, t-1}
\end{array}\right],
$$

where

$$
\begin{aligned}
& \delta=\frac{1}{\lambda}\left[\begin{array}{ll}
\gamma_{1}^{(1)}+\gamma_{1}^{(2)} & \gamma_{2}^{(1)}+\gamma_{2}^{(2)}
\end{array}\right] I_{2}\left[\begin{array}{l}
\mu_{1} / \sigma_{1} \\
\mu_{2} / \sigma_{2}
\end{array}\right], \\
& \lambda=\left[\begin{array}{ll}
\gamma_{1}^{(1)} & \gamma_{2}^{(1)}
\end{array}\right] I_{2}\left[\begin{array}{l}
1 / \sigma_{1} \\
1 / \sigma_{2}
\end{array}\right], \\
& {\left[\begin{array}{ll}
\gamma_{1}^{(1)} & \gamma_{2}^{(1)}
\end{array}\right]=\left[\begin{array}{lll}
1 & 0 & 0
\end{array}\right] P B^{\prime}\left[B P B^{\prime}+E\right]^{-1}}
\end{aligned}
$$

and

$$
\left[\begin{array}{ll}
\gamma_{1}^{(2)} & \gamma_{2}^{(2)}
\end{array}\right]=\left[\begin{array}{lll}
1 & 0 & 0
\end{array}\right]\left\{\left(I_{3}-P B^{\prime}\left[B P B^{\prime}+E\right]^{-1} B\right) A\right\} P B^{\prime}\left[B P B^{\prime}+E\right]^{-1} .
$$

For the estimation, the fact that we use the normalised signal series $Y_{t}$ instead of the original growth rates $X_{t}$ implies a reduction of parameters to be fitted by maximum likelihood. To see this, let us focus on $Y_{1, t}$, which is given by Eq. (3) as

$$
Y_{1, t}=\beta_{11} \Delta C_{t}+\beta_{12} \Delta C_{t-1}+\varepsilon_{1, t} .
$$

It is possible to estimate $\beta_{11}, \beta_{12}$ and the variance of $\varepsilon_{1, t}$ directly. However, since $Y_{1, t}$ has been normalised to have a unit variance, squaring Eq. (5) and taking expectations yields

$$
1=\left(\beta_{11}^{2}+\beta_{12}^{2}\right) \operatorname{var}\left(\Delta C_{t}\right)+\sigma_{\varepsilon 1}^{2} .
$$

From Eq. (4), we have that

$$
\operatorname{var}\left(\Delta C_{t}\right)=\alpha^{2} \operatorname{var}\left(\Delta C_{t}\right)+\sigma_{u}^{2} .
$$

Given the identifying assumption that $\sigma_{u}^{2}=1$,

$$
\operatorname{var}\left(\Delta C_{t}\right)=\frac{1}{1-\alpha^{2}},
$$

implying that

$$
\sigma_{\varepsilon 1}^{2}=1-\frac{\beta_{11}^{2}+\beta_{12}^{2}}{1-\alpha^{2}} .
$$

Thus, we need to fit only two instead of three parameters in Eq. (5). 


\section{Appendix B: Level Estimate of economic activity}

While growth data are required for many applications in economic history, the assessment of the level of real output is of more general interest. We therefore provide our implied estimates of the level of economic activity in Switzerland for the period 1886 to 1930 . SW show that real activity can be calculated as

$$
C_{t}=\exp \sum_{s=1}^{t} \Delta C_{s}
$$

where we normalise $C_{1886}$ to 100 . Table 9 shows the estimates derived from the PC and the UC index. ${ }^{20}$ We also present estimates of nominal economic activity obtained by multiplying with the CPI from Bordo and Jonung [2]. Furthermore, we normalise those series by the value of nominal national income in 1929 from the Swiss National Bank [12].

The upper panel in Fig. 6 plots the level of the real PC and the UC index together with the estimate of real activity by AAW and the actual real national income data (normalised so they link together in 1929), while the lower plot shows the corresponding nominal series.
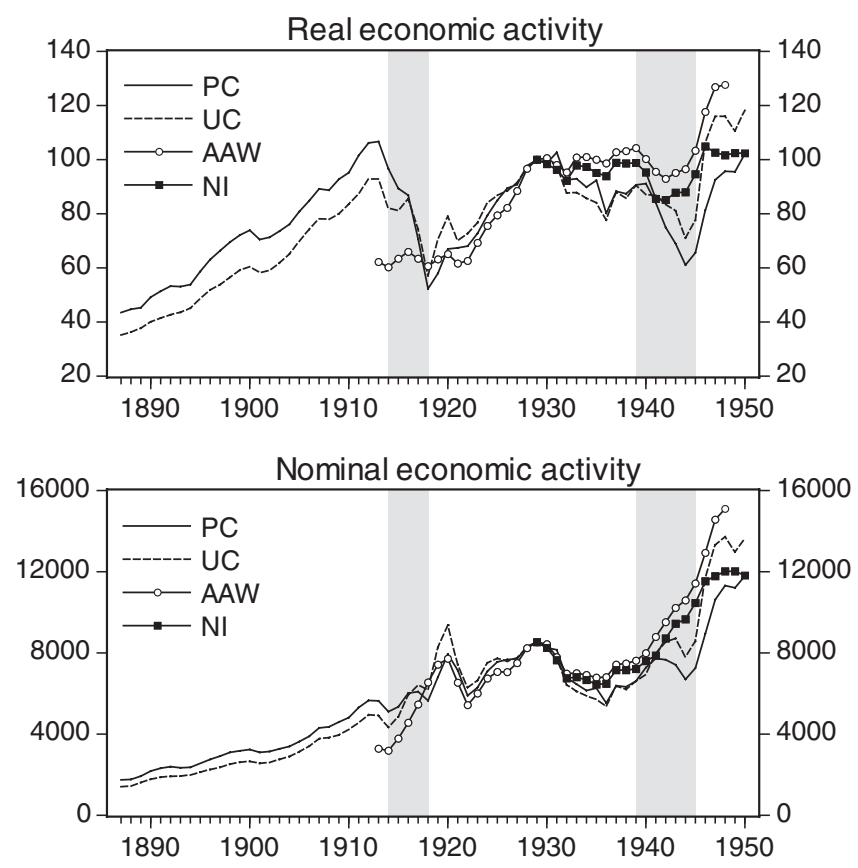

Fig. 6. $\mathrm{PC}, \mathrm{UC}$ and $\mathrm{AAW}$ indices with actual national income

\footnotetext{
${ }^{20}$ The different estimates of the average growth rate of the PC and UC index result in differences in the implied level of economic activity.
} 
Table 9. Economic activity (level data)

\begin{tabular}{|c|c|c|c|c|c|c|c|c|c|}
\hline & \multicolumn{2}{|l|}{ Real } & \multicolumn{2}{|c|}{ Nominal } & & \multicolumn{2}{|l|}{ Real } & \multicolumn{2}{|l|}{ Nominal } \\
\hline & $\mathrm{PC}$ & $\mathrm{UC}$ & $\mathrm{PC}$ & $\mathrm{UC}$ & & $\mathrm{PC}$ & $\mathrm{UC}$ & $\mathrm{PC}$ & $\mathrm{UC}$ \\
\hline 1886 & 100.0 & 100.0 & 1639.6 & 1344.8 & 1919 & 138.3 & 204.7 & 6808.4 & 8265.9 \\
\hline 1887 & 103.9 & 102.5 & 1749.2 & 1415.0 & 1920 & 159.9 & 229.9 & 7941.2 & 9365.5 \\
\hline 1888 & 106.8 & 105.7 & 1774.6 & 1440.2 & 1921 & 160.9 & 203.8 & 7144.9 & 7424.6 \\
\hline 1889 & 108.1 & 109.8 & 1938.3 & 1614.5 & 1922 & 162.4 & 211.4 & 5900.6 & 6301.0 \\
\hline 1890 & 117.4 & 116.7 & 2180.7 & 1779.1 & 1923 & 173.6 & 223.0 & 6304.7 & 6642.9 \\
\hline 1891 & 122.6 & 120.7 & 2324.2 & 1877.5 & 1924 & 189.6 & 244.6 & 7097.2 & 7509.8 \\
\hline 1892 & 127.1 & 124.1 & 2398.8 & 1921.4 & 1925 & 202.7 & 252.5 & 7559.7 & 7724.4 \\
\hline 1893 & 126.8 & 126.9 & 2349.8 & 1929.2 & 1926 & 213.4 & 257.2 & 7674.2 & 7588.6 \\
\hline 1894 & 128.5 & 131.4 & 2367.1 & 1985.4 & 1927 & 216.7 & 266.2 & 7703.8 & 7761.5 \\
\hline 1895 & 140.1 & 141.7 & 2566.2 & 2129.6 & 1928 & 233.2 & 282.1 & 8324.0 & 8259.7 \\
\hline 1896 & 150.6 & 150.9 & 2754.1 & 2263.9 & 1929 & 238.6 & 290.9 & 8529.0 & 8529.0 \\
\hline 1897 & 158.4 & 156.7 & 2922.3 & 2370.8 & 1930 & 235.3 & 289.3 & 8265.0 & 8335.5 \\
\hline 1898 & 165.8 & 164.4 & 3100.1 & 2520.6 & 1931 & 244.9 & 285.0 & 8155.9 & 7785.4 \\
\hline 1899 & 172.1 & 172.2 & 3182.5 & 2612.3 & 1932 & 220.7 & 254.9 & 6777.1 & 6420.0 \\
\hline 1900 & 176.3 & 175.8 & 3245.3 & 2654.5 & 1933 & 221.7 & 255.3 & 6458.8 & 6101.3 \\
\hline 1901 & 168.2 & 169.3 & 3100.3 & 2559.1 & 1934 & 214.3 & 249.3 & 6152.7 & 5872.2 \\
\hline 1902 & 170.1 & 171.7 & 3148.8 & 2606.9 & 1935 & 220.5 & 244.4 & 6266.8 & 5699.3 \\
\hline 1903 & 175.6 & 179.9 & 3274.4 & 2751.8 & 1936 & 191.2 & 225.9 & 5529.4 & 5357.8 \\
\hline 1904 & 181.6 & 189.4 & 3390.9 & 2899.9 & 1937 & 210.7 & 255.9 & 6387.2 & 6361.9 \\
\hline 1905 & 192.8 & 203.0 & 3629.1 & 3134.4 & 1938 & 208.6 & 248.9 & 6336.8 & 6203.1 \\
\hline 1906 & 202.3 & 215.9 & 3893.2 & 3409.1 & 1939 & 216.3 & 263.3 & 6618.7 & 6608.5 \\
\hline 1907 & 212.8 & 227.3 & 4302.9 & 3770.0 & 1940 & 217.5 & 253.1 & 7272.2 & 6941.7 \\
\hline 1908 & 211.5 & 226.5 & 4357.8 & 3826.7 & 1941 & 200.5 & 252.4 & 7733.3 & 7981.9 \\
\hline 1909 & 221.4 & 232.8 & 4595.0 & 3963.5 & 1942 & 178.8 & 242.7 & 7667.9 & 8536.4 \\
\hline 1910 & 227.1 & 243.1 & 4819.9 & 4230.8 & 1943 & 164.5 & 235.7 & 7410.3 & 8712.9 \\
\hline 1911 & 242.3 & 254.0 & 5308.3 & 4563.5 & 1944 & 145.6 & 206.8 & 6700.8 & 7803.3 \\
\hline 1912 & 253.4 & 270.1 & 5662.7 & 4952.8 & 1945 & 156.7 & 225.7 & 7257.2 & 8577.0 \\
\hline 1913 & 254.4 & 270.1 & 5635.6 & 4908.0 & 1946 & 194.1 & 309.1 & 8942.3 & 11683.8 \\
\hline 1914 & 230.5 & 238.6 & 5111.1 & 4340.1 & 1947 & 220.7 & 337.2 & 10622.8 & 13316.6 \\
\hline 1915 & 213.2 & 236.0 & 5341.4 & 4849.5 & 1948 & 228.3 & 337.4 & 11318.9 & 13723.1 \\
\hline 1916 & 207.1 & 248.7 & 6016.9 & 5925.9 & 1949 & 228.0 & 321.7 & 11206.3 & 12973.7 \\
\hline 1917 & 168.6 & 216.4 & 6093.0 & 6415.6 & 1950 & 243.8 & 343.7 & 11790.1 & 13634.1 \\
\hline 1918 & 124.9 & 166.4 & 5648.9 & 6167.5 & & & & & \\
\hline
\end{tabular}

Note: Constructed using weights estimated for the period 1886 to 1930.

\section{References}

1. Andrist F, Anderson RG, Williams MM (2000) Real output in Switzerland: New estimates for 1914-1947. Federal Reserve Bank of St. Louis Review, May/June, pp. 43-69

2. Bergman UM, Bordo MD, Jonung L (1998) Historical evidence on business cycles: The international experience. In: Fuhrer JC, Schuh S (eds.) Beyond shocks: What causes business cycles? Federal Reserve Bank of Boston, Conference Series 42, June

3. Eidgenössisches Statistisches Amt (1940) Statistisches Jahrbuch der Schweiz

4. Gerlach S, Gerlach-Kristen P (2002) Estimates of real economic activity in Switzerland, 1885-1930. CEPR Working Paper 3427

5. Hamilton J D (1994) Time series analysis. Princeton University Press, Princeton

6. Johnston J (1984) Econometric methods. McGraw-Hill, New York

7. Mardia KV, Kent JT, Bibby JM (1979) Multivariate analysis. Academic Press, London

8. Mitchell BR (1998) International historical statistics. Europe 1750-1993. MacMillan, London

9. Ritzmann-Blickenstorfer H (1996) Historische Statistik der Schweiz. Chronos Verlag, Zürich 
10. Stock JH, Watson MW (1989) New indexes of coincident and leading economic indicators. In: Blanchard OJ, Fischer S (eds.) NBER macroeconomics annual 1989. MIT Press, Cambridge MA

11. Stock JH, Watson MW (1991) A probability model of the coincident economic indicators. In: Lahari K, Moore GH (eds.) Leading economic indicators. Cambridge University Press Cambridge MA

12. Swiss National Bank (1944) Statistisches Handbuch des schweizerischen Geld- und Kapitalmarktes, Mitteilungen der volkswirtschaftlichen Abteilung der Schweizerischen Nationalbank, 26. Heft. Schulthess \& Co., Zürich 